\title{
PROSPECTIVE EVALUATION OF THORACIC ULTRASOUND IN THE DETECTION OF PNEUMOTHORAX
}

KW Schwarz, MD*, DR Hamilton, $\mathrm{MD}, \mathrm{PhD}^{\sharp}$, AW Kirkpatrick, MD", RD Billica, $\mathrm{MD}^{\dagger}, \mathrm{DR}$ Williams, $\mathrm{MD}^{\dagger}, \mathrm{LN}$ Diebel, MD*, AE Sargysan, MD\#, SA Dulchavsky, $\mathrm{MD}, \mathrm{PhD}^{* \dagger}$, *Wayne State Univ., Detroit, MI; ${ }^{\dagger}$ NASA Johnson Space Center, Houston, TX, \#Wyle Laboratories, Houston, TX, and "Vancouver Genl. Hosp., Vancouver, BC

Introduction: Pneumothorax (PTX) occurs commonly in trauma patients and is confirmed by examination and radiography. Thoracic ultrasound (U/S) has been suggested as an alternative method for rapidly diagnosing PTX when X-ray is unavailable as in rural, military, or space flight settings; however, its accuracy and specificity are not known.

Methods: We evaluated the accuracy of thoracic U/S detection of PTX compared to radiography in stable, emergency patients with a high suspicion of PTX at a Level-1 trauma center over a 6-month period. Following University and NASA Institutional Review Board approval, informed consent was obtained from patients with penetrating or blunt chest trauma, or with a history consistent with PTX. Whenever possible, the presence or absence of the "lung sliding" sign or the "comet tail" artifact were determined by U/S in both hemithoraces by residents instructed in thoracic U/S before standard radiologic verification of PTX. Results were recorded on data sheets for comparison to standard radiography.

Results:

\begin{tabular}{lcclll}
\hline Mechanism & Screened Pts & X-Ray PTX & U/S PTX & False (+) & False (-) \\
\hline Blunt & 255 & 10 & $9 / 10$ & 0 & $1 / 10$ \\
Gunshot & 18 & 5 & $5 / 5$ & 0 & 0 \\
Stab & 51 & 8 & $8 / 8$ & 0 & 0 \\
Spontaneous & 15 & 10 & $9 / 10$ & 0 & $1 / 10$ \\
\hline TOTAL & 342 & $33 / 33$ & $31 / 33$ & $0 / 33$ & $2 / 33$
\end{tabular}

Thoracic U/S had a 94\% sensitivity; two PTX could not be reliably diagnosed due to subcutaneous air; the true negative rate was $100 \%$. In one patient, the U/S exam was positive while $\mathrm{X}$ ray did not confirm PTX; a follow-up film 1 hour later demonstrated a small PTX. The average time for bilateral thoracic U/S examination 
was 2 to 3 minutes. Conclusions: Thoracic ultrasound reliably diagnoses pneumothorax. Presence of the "lung sliding" sign conclusively excludes pneumothorax. Expansion of the FAST examination to include the thorax should be investigated. 